\title{
ANO7 rs77559646 Is Associated With First-line Docetaxel Treatment Response in Metastatic Castration-resistant Prostate Cancer
}

\author{
ELINA KAIKKONEN ${ }^{1}$, OTTO ETTALA ${ }^{2}$, ILKKA NIKULAINEN ${ }^{2,3}$, PEKKA TAIMEN $^{4}$, ILARI LEHTINEN ${ }^{5}$, \\ PETER J. BOSTRÖM ${ }^{2}$, PIRKKO-LIISA KELLOKUMPU-LEHTINEN ${ }^{6,7}$ and JOHANNA SCHLEUTKER ${ }^{1,8}$ \\ ${ }^{1}$ Institute of Biomedicine, University of Turku, Turku, Finland; \\ ${ }^{2}$ Department of Urology, Turku University Hospital, Turku, Finland; \\ ${ }^{3}$ Department of Surgery, Satakunta Central Hospital, Pori, Finland; \\ ${ }^{4}$ Department of Pathology, University of Turku and Turku University Hospital, Turku, Finland; \\ ${ }^{5}$ Faculty of Information Technology and Communication Sciences, University of Tampere, Tampere, Finland; \\ ${ }^{6}$ Faculty of Medicine and Life Sciences, University of Tampere, Tampere, Finland; \\ ${ }^{7}$ Department of Oncology, Tampere University Hospital, Tampere, Finland; \\ ${ }^{8}$ Department of Medical Genetics, Genomics, Laboratory Division, Turku University Hospital, Turku, Finland
}

\begin{abstract}
Background: Identification of genetic prognostic biomarkers, such as germline variants, are urgently needed to choose optimal treatment for metastatic castrationresistant prostate cancer ( $m C R P C)$. Patients and Methods: The prognostic value of anoctamin 7 (ANO7) rs77559646 on docetaxel response was tested in a prospective PROSTY randomized trial and a retrospective Auria Biobank set. The variant rs 77559646 was genotyped and its association with progression-free survival (PFS) and overall survival (OS) was tested. Results: In comparison with the non-carriers, the variant carriers had longer PFS $(p=0.005)$ and OS $(p=0.003)$ in the PROSTY cohort. In the retrospective cohort, there was a borderline association with PFS ( $p=0.09)$, but not in $O S(p=0.9)$. In both cohorts, Cox regression multivariate models revealed that rs77559646 was an independent prognostic factor for favourable PFS. Conclusion: The rs 77559646 was shown to be a prognostic germline biomarker for better response to docetaxel treatments. To our knowledge, this is the first time that a non-coding germline variant has been associated with chemotherapy of $m C R P C$.
\end{abstract}

This article is freely accessible online.

Correspondence to: Johanna Schleutker, Institute of Biomedicine, University of Turku, Kiinamyllynkatu 10, 20520 Turku, Finland. Tel: +358294502726, e-mail: Johanna.Schleutker@utu.fi

Key Words: ANO7, CRPC, docetaxel, prostate cancer.
One in five cases of prostate cancer ( $\mathrm{PCa}$ ) progresses after local therapies and will eventually progress into a castrationresistant prostate cancer (CRPC) when treated with androgen deprivation therapy (ADT). Treatment options for metastatic CRPC (mCRPC) include taxanes (docetaxel and cabazitaxel) and androgen receptor-targeting therapies (abiraterone acetate and enzalutamide).

Choosing the right therapy for each patient is very problematic and more frequently based on the age, symptoms, and general condition of the patient than on the molecular characteristics of the tumor $(1,2)$. On the other hand, the first-line therapy usually has the best response, emphasizing the importance of the first drug selected. Docetaxel has been the gold standard in treating mCRPC since its approval by the US Food and Drug Administration in 2004 based on two randomized clinical trials $(3,4)$. Unlike docetaxel, the new second-line hormonal therapies abiraterone acetate and enzalutamide have been in clinical use for a shorter time, since 2011 and 2012 respectively. Due to its adverse effects, not all patients with mCRPC can be treated with docetaxel and the newest Advanced Prostate Cancer Consensus Conference guidelines (2) concluded that abiraterone acetate or enzalutamide should be recommended before docetaxel as first-line treatment for asymptomatic patients with mCRPC.

PCa has a very strong genetic background, with $57 \%$ of the inter-individual variation in risk being attributed to genetic factors (5). In our recent study(6), we showed that anoctamin 7 (ANO7) rs77559646 is related to PCa susceptibility and aggressive phenotype. ANO7 is prostate specific (6-8) and its expression is elevated in $\mathrm{PCa}$ compared to benign prostate 
tissue $(6,8)$. The function of ANO7 protein is still unclear, but is predicted to act as scramblase (9) or calcium-activated chloride ion channel $(10,11)$. According to in silico analyses, ANO7 rs77559646 mutation causes a splice site mutation in the long transcript of $A N O 7$ intron 4 and a missense mutation in the short form. The frequency of this ANO7 variant in $\mathrm{PCa}$ among Finnish, Swedish and Norwegian patients is $9.4 \%, 4 \%$ and $3.5 \%$, respectively (6). Although the rs77559646 variant is associated with aggressive disease, the survival of the carriers of this single nucleotide polymorphism (SNP) has not been reported to differ from that of non-carriers (6). Therefore, we hypothesized that their relatively good survival might be due to better cytotoxic treatment response to docetaxel among ANO7 rs77559646 variant carriers. This hypothesis was tested in two cohorts of patients with mCRPC treated with docetaxel.

\section{Materials and Methods}

Study design and patient cohorts. The genetic association study was conducted using two cohorts of patients who received first-line docetaxel for mCRPC: A set of 98 Finnish patients from PROSTY (NCT00255606)(12), a randomized, registered, prospective trial; and 110 retrospectively collected samples from the Auria Biobank (the Auria cohort; Turku, Finland).

A total of 361 patients were recruited between 2004-2009 into the multinational prospective randomized PROSTY trial. The inclusion criteria relevant for the current study were: Castrationresistant metastatic disease, a WHO performance status of 0-2 and a prostate-specific antigen (PSA) concentration more than $10 \mathrm{ng} / \mathrm{ml}$, followed by a rise in two or more consecutive measurements. Exclusion criteria included any history of cancer other than $\mathrm{PCa}$, any medical condition preventing administration of chemotherapy, impaired liver or kidney tests, low blood neutrophil count or low concentration of hemoglobin (12).

In the Auria cohort, 110 patients were retrospectively identified from the patient records by ICD-10 code (C61) and ATC codes (L01CD02). The data of these patients was manually collected from electronic healthcare records. The patients were treated with docetaxel at Turku University Hospital (Turku, Finland) between 2007 and 2018. The key inclusion criteria were: Administration of at least two cycles of docetaxel as first-line treatment in men with CRPC and having blood or tissue sample available for genotyping. Patients treated with early chemohormonal treatment (i.e. administration of docetaxel less than 90 days after initiation of ADT in hormone-sensitive patients) or men receiving fewer than two cycles of docetaxel were excluded.

DNA extraction. All PROSTY cohort samples were formalin-fixed and paraffin-embedded (FFPE) and obtained from prostate biopsy or prostatectomy tissues. The Auria cohort consisted of 24 blood samples, 17 prostate FFPE tissues, and 69 FFPE samples from tissues other than prostate. Five patients from the Auria cohort were excluded due to unavailability of blood or tissue. DNA was extracted using Qiagen DNA micro extraction and QiaAmp FFPE DNA kits (Qiagen, Hilden, Germany). Blood DNA was extracted with Nucleon BACC3 kit (GE Healthcare, Merck, Chicago, IL, USA). DNA concentrations were measured with Qubit Fluorometer (ThermoFisher Scientific, Inc., Waltham, MA, USA).
SNP genotyping. Patient samples were genotyped using commercial Taqman SNP genotyping assay for ANO7 rs77559646 (ThermoFisher Scientific, Inc.), 10\% of the genotyped DNAs was randomly chosen for Sanger sequencing validation. Although some of the genotyped samples were somatic DNA, all detected SNPs were considered as germline based on our earlier results (6).

Study endpoints. The primary endpoint was progression-free survival (PFS), which was defined as time from initiation of chemotherapy to biochemical or radiological progression, whichever came first, or patient death. The secondary endpoint was overall survival (OS), defined as time from initiation of chemotherapy to death from any cause.

Evaluation of docetaxel treatment response and progression. In both cohorts, the treatment response and progression were evaluated with the same methods. Radiographic response and progression were evaluated using bone scan, whole-body computed tomography or magnetic resonance imaging and graded according to RECIST 1.1. (13). In bony lesions, response was defined as either "stable disease" (no change in number of bony lesions) or complete response (disappearance of all the lesions seen in the baseline). Progression was defined as two or more new lesions observed either in X-rays, computed tomography or magnetic resonance imaging.

Biochemical response was defined as a minimum of $50 \%$ decrease in PSA concentration at least 4 weeks after the administration of the first dose of docetaxel and in the PROSTY trial according to the protocol (12), which was every sixth week in both docetaxel dosing arms. An increase of $25 \%$ in PSA concentration above the PSA nadir was defined as PSA progression.

Since a proportion of the patients included in both cohorts were diagnosed with PCa more than 20 years ago, there is uncertainty about the baseline variables for these patients, especially the exact date of ADT initiation. Therefore, the time interval between the diagnosis of PCa and date of first docetaxel cycle was used as a surrogate marker to describe the time interval between the initiation of ADT and chemotherapy.

Statistical analyses. SAS JMP Pro (version 13.1.0) (SAS Institute, Cary, NC, USA) was used for the data analysis. All analyses were twosided and p-values below 0.05 were considered statistically significant. PFS and OS of carriers and non-carriers were estimated with KaplanMeier method and log-rank tests. In the Cox proportional hazard model, the relevance of rs77559646 and clinical variables on disease PFS time was investigated. Hazard ratios (HR) and 95\% confidence intervals $(\mathrm{CI})$ were calculated for the models. The clinical covariates were as follows: Gleason score (dichotomized into two groups: $\leq 7$ or $\geq 8$ ), pre-treatment PSA ( $\mathrm{ng} / \mathrm{ml}$, continuous), time from diagnosis to chemotherapy (continuous), and rs77559646 genotype.

\section{Results}

The patient characteristics for both cohorts and separately for variant carriers and non-carriers are presented in Table I. A heterozygous ANO7 rs77559646 variant was detected in six $(6 \%)$ of PROSTY and $11(10 \%)$ of the Auria patients. None of the genotyped mCRPC cases were homozygous for the mutation. Biochemical response (PSA decline) to docetaxel was observed in five out of six $(83 \%)$ variant carriers and in 
Table I. Patient characteristics.

\begin{tabular}{|c|c|c|c|c|c|c|}
\hline & \multicolumn{2}{|c|}{ All } & \multicolumn{2}{|c|}{ rs77559646 carriers } & \multicolumn{2}{|c|}{ rs77559646 non-carriers } \\
\hline & PROSTY n=98 & Auria $n=110$ & PROSTY $n=6$ & Auria $n=11$ & PROSTY n=92 & Auria $n=99$ \\
\hline \multicolumn{7}{|c|}{ Age at diagnosis, years } \\
\hline Median (IQR) & $65(61-71)$ & $67(62-72)$ & $62(54-63)$ & $70(65-73)$ & $66(61-71)$ & $67(62-71)$ \\
\hline \multicolumn{7}{|l|}{ Age at death, years } \\
\hline Median (IQR) & $71(67-77)$ & $74(71-78)$ & $70(64-72)$ & $78(73-81)$ & $72(68-77)$ & $74(71-77)$ \\
\hline \multicolumn{7}{|l|}{ Status } \\
\hline Dead & $87(94 \%)$ & $72(65 \%)$ & $6(100 \%)$ & $7(64 \%)$ & $81(93 \%)$ & $65(66 \%)$ \\
\hline Alive & $6(6 \%)$ & $38(35 \%)$ & 0 & $4(36 \%)$ & $6(7 \%)$ & $34(34 \%)$ \\
\hline Missing data & 5 & 0 & 0 & 0 & 5 & 0 \\
\hline \multicolumn{7}{|l|}{ Metastases, n (\%) } \\
\hline Bone & $83(85 \%)$ & $91(83 \%)$ & $4(67 \%)$ & $9(82 \%)$ & $73(86 \%)$ & $82(83 \%)$ \\
\hline Visceral & $8(8 \%)$ & $11(10 \%)$ & 0 & $1(9 \%)$ & $8(9 \%)$ & $10(10 \%)$ \\
\hline Lymph nodes & $43(44 \%)$ & $45(41 \%)$ & $2(33 \%)$ & $6(55 \%)$ & $37(44 \%)$ & $39(39 \%)$ \\
\hline$>1$ site & $32(33 \%)$ & $33(30 \%)$ & 0 & $5(45 \%)$ & $28(33 \%)$ & $28(28 \%)$ \\
\hline Missing data & 0 & 4 & 0 & 1 & 0 & 3 \\
\hline \multicolumn{7}{|l|}{ Gleason, n (\%) } \\
\hline$\leq 7$ & $21(24 \%)$ & $42(47 \%)$ & $2(40 \%)$ & $4(44 \%)$ & $19(23 \%)$ & $38(48 \%)$ \\
\hline$\geq 8$ & $65(76 \%)$ & $47(53 \%)$ & $3(60 \%)$ & $5(56 \%)$ & $62(77 \%)$ & $42(52 \%)$ \\
\hline Missing data & 12 & 21 & 1 & 2 & 11 & 19 \\
\hline \multicolumn{7}{|c|}{ PSA pre docetaxel $\mathrm{ng} / \mathrm{ml}$} \\
\hline Median (IQR) & $92(38.1-229)$ & $17.5(8.58-81.2)$ & $46(18.3-315)$ & $44(10.7-140)$ & $92(39.2-232)$ & $17(8.20-75.0)$ \\
\hline \multicolumn{7}{|l|}{$\begin{array}{l}\text { PFS after docetaxel } \\
\text { initiation, days }\end{array}$} \\
\hline Median $(95 \% \mathrm{CI})$ & $168(137-216)$ & $181(153-199)$ & $587(84-631)$ & $161(94-382)$ & $157(131-209)$ & $181(148-199)$ \\
\hline \multicolumn{7}{|l|}{$\begin{array}{l}\text { OS after docetaxel } \\
\text { initiation, days }\end{array}$} \\
\hline Median $(95 \% \mathrm{CI})$ & 689 (511-799) & $679(620-786)$ & $1477(238-2716)$ & $804(363-1088)$ & $663(479-793)$ & $675(620-739)$ \\
\hline \multicolumn{7}{|c|}{$\begin{array}{l}\text { Biochemical/radiological } \\
\text { response }\end{array}$} \\
\hline Yes & $81(84 \%)$ & $84(76 \%)$ & $6(100 \%)$ & $8(73 \%)$ & $75(83 \%)$ & $76(77 \%)$ \\
\hline No & $15(16 \%)$ & $41(37 \%)$ & 0 & $3(27 \%)$ & $15(17 \%)$ & $23(23 \%)$ \\
\hline Missing data & 2 & 0 & 0 & 0 & 2 & 0 \\
\hline \multicolumn{7}{|l|}{$\begin{array}{l}\text { Diagnosis to } \\
\text { docetaxel, days }\end{array}$} \\
\hline Median $(95 \% \mathrm{CI})$ & $1409(1142-1783)$ & $1758(1560-2089)$ & $1431(407-39427)$ & $1114(546-3455)$ & $1358(1141-1810)$ & $1852(1580-2101)$ \\
\hline \multicolumn{7}{|l|}{ M Stage at diagnosis } \\
\hline M1 & & $23(23 \%)$ & & $5(50 \%)$ & & $18(20 \%)$ \\
\hline M0 & & $77(77 \%)$ & & $5(50 \%)$ & & $72(80 \%)$ \\
\hline Missing & 98 & 17 & 6 & 2 & 92 & 15 \\
\hline \multicolumn{7}{|l|}{$\mathrm{N}$ stage at diagnosis } \\
\hline N1 & & $24(26 \%)$ & & $5(45 \%)$ & & $19(23 \%)$ \\
\hline No & & $70(74 \%)$ & & $6(55 \%)$ & & $64(77 \%)$ \\
\hline Missing & 98 & 23 & 6 & 1 & 92 & 22 \\
\hline \multicolumn{7}{|c|}{$\begin{array}{l}\text { Abiraterone/enzalutamide } \\
\text { after docetaxel }\end{array}$} \\
\hline Yes & 0 & $79(72 \%)$ & 0 & $7(64 \%)$ & 0 & $72(73 \%)$ \\
\hline
\end{tabular}

CI: Confidence interval; IQR: interquartile range; M: distal metastases; N: regional metastases; OS: overall survival; PFS: progression-free survival; PSA: prostate-specific antigen.

65 out of $92(71 \%)$ non-carriers in the PROSTY cohort, while $8 / 11$ carriers $(73 \%)$ and $61 / 99$ non-carriers $(62 \%)$ in the Auria cohort showed a PSA response.

The median PFS for variant carriers and non-carriers was 20 months and 5 months, respectively, in the PROSTY cohort. In the Auria cohort, the median PFS was 5 months for carriers and 6 months for non-carriers. Median OS was 49 months for carriers, and 23 months for non-carriers in the PROSTY cohort, while the corresponding values for the Auria cohort were 27 and 28 months. 
Kaplan-Meier PFS and OS curves for PROSTY and Auria cohorts are shown in Figure 1. Interestingly, rs77559646 variant carriers had longer median PFS in both PROSTY $(p=0.005)$, and Auria cohorts, although the difference was not statistically significant in the latter cohort $(p=0.09)$. In PROSTY, the variant carriers had significantly improved OS $(p=0.003)$, but in Auria, the OS did not differ between the two groups $(p=0.9)$.

Cox proportional hazard multivariate analysis results for PFS are presented in Table II. ANO7 variant rs77559646 was a statistically significant predictor of improved PFS in both cohorts (non-carriers vs. carriers: PROSTY HR 3.9, 95\% CI=1.5-12, $p=0.0027$; Auria $\mathrm{HR}=2.4,95 \% \mathrm{CI}=1.1-6.1, p=0.024)$. An additional statistically significant covariate in PROSTY was Gleason score ( $\geq 8 v s . \leq 7 \mathrm{HR}=1.8,95 \% \mathrm{CI}=1.0-3.1, p=0.040)$, but in Auria there were no other significant covariates besides rs77559646.

\section{Discussion}

Currently there are many unmet needs in PCa diagnostics and prognostics. Blood-based biomarkers are of great clinical interest because they can aid in decision-making processes. The ANO7 rs77559646 germline mutation was shown to be associated with an aggressive PCa in our earlier study (6). In the current study, we demonstrate that this particular SNP is also associated with better PFS in patients treated with first-line docetaxel.

Contrary to the PROSTY cohort, where a better OS was observed, no statistically significant difference in OS was seen in the Auria cohort between ANO7 variant carriers and non-carriers. This is likely due to clinical differences between the two cohorts. The PROSTY cohort was derived from a prospective, well-defined and controlled phase III multi-center trial, whereas the Auria cohort samples were collected retrospectively from the Turku University Hospital registries. The structured fashion of imaging and PSA measurements in PROSTY is in contrast with the data collection for Auria, where imaging and blood chemistry measurements were performed at uneven intervals. Patients in the Auria cohort are therefore more representative of unselected patients compared with the very controlled PROSTY cohort. The other major dissimilarity between these two cohorts is that none of the PROSTY patients received abiraterone acetate or enzalutamide after docetaxel, while $72 \%$ of patients in Auria cohort received new secondor third-line androgen pathway modulators. The latter may in fact explain why no survival benefit was observed in the Auria cohort. Since non-carriers of ANO7 SNP did not respond to docetaxel as well as the SNP carriers, most of the non-carriers received abiraterone and enzalutamide as a second-line treatment, which likely improved their survival and possibly masked the good response of docetaxel in $S N P$ carriers. However, it was not possible to determine the effect of abiraterone and enzalutamide on OS reliably due to the small number of SNP carriers in the subgroups (data not shown).

Taxanes were originally shown to inhibit cell mitosis by binding to microtubules and thus blocking microtubule reorganization (14). They are also thought to have an effect on androgen receptor translocation into the nucleus (15). Since the exact function of ANO7 is not known, the impact of the $A N O 7$ variant on the response of docetaxel is not clear. One study has suggested that ANO7 expression is androgenregulated (8), which might be related to the mechanism behind docetaxel effectiveness as taxanes purportedly have an impact on androgen receptor transportation into the nucleus (16)

There are only few molecular markers possibly predicting mCRPC treatment response. One of the most studied is the androgen receptor splice variant AR-V7, which has been reported to be associated with a poor response to abiraterone acetate and enzalutamide (17). Docetaxel, in turn, seems to be effective for these patients (18). Additionally, some predictive clinical variables and cell-free DNA-based detection methods have been investigated (19). For germline markers, Castro et al. sequenced DNA repair genes and found that BRCA2 DNA repair-associated gene (BRCA2) mutation carriers had better survival when treated with abiraterone acetate or enzalutamide than with taxanes (20). However, instead of using particular SNPs, they combined all detected variants. The current analysis is the first study reporting a single germline variant associated with aggressive PCa and with outcome of MCRPC after docetaxel treatment. This is an especially important finding taking into account the possible adjuvant use of docetaxel in high-risk $\mathrm{PCa}$ (21-23). Moreover, ANO7 is not a DNA-repair gene, therefore revealing there must be another pathway underlying the response to docetaxel. The advantage of a germline marker compared to other diagnostic methods is that there is no need to have tissue from the tumor, i.e. it is non-invasive. The SNP can be tested from a simple blood sample or any tissue obtained, including FFPE samples. In addition, germline SNPs remain stable over time despite the patient being given treatments, or other factors and, most importantly, it is present in all cancer clones unlike somatic mutations that can differ between metastatic sites. Thus, the sensitivity and specificity of such tests are better than those with using other methods.

There are two major limitations to our study. The first is the relatively low prevalence of the ANO7 variant even though this variant is enriched among aggressive PCa cases. A second limitation is the retrospective nature of the Auria cohort. Therefore, although the results are encouraging, they should be considered as preliminary and another larger prospective study is warranted. The major pitfall in the 

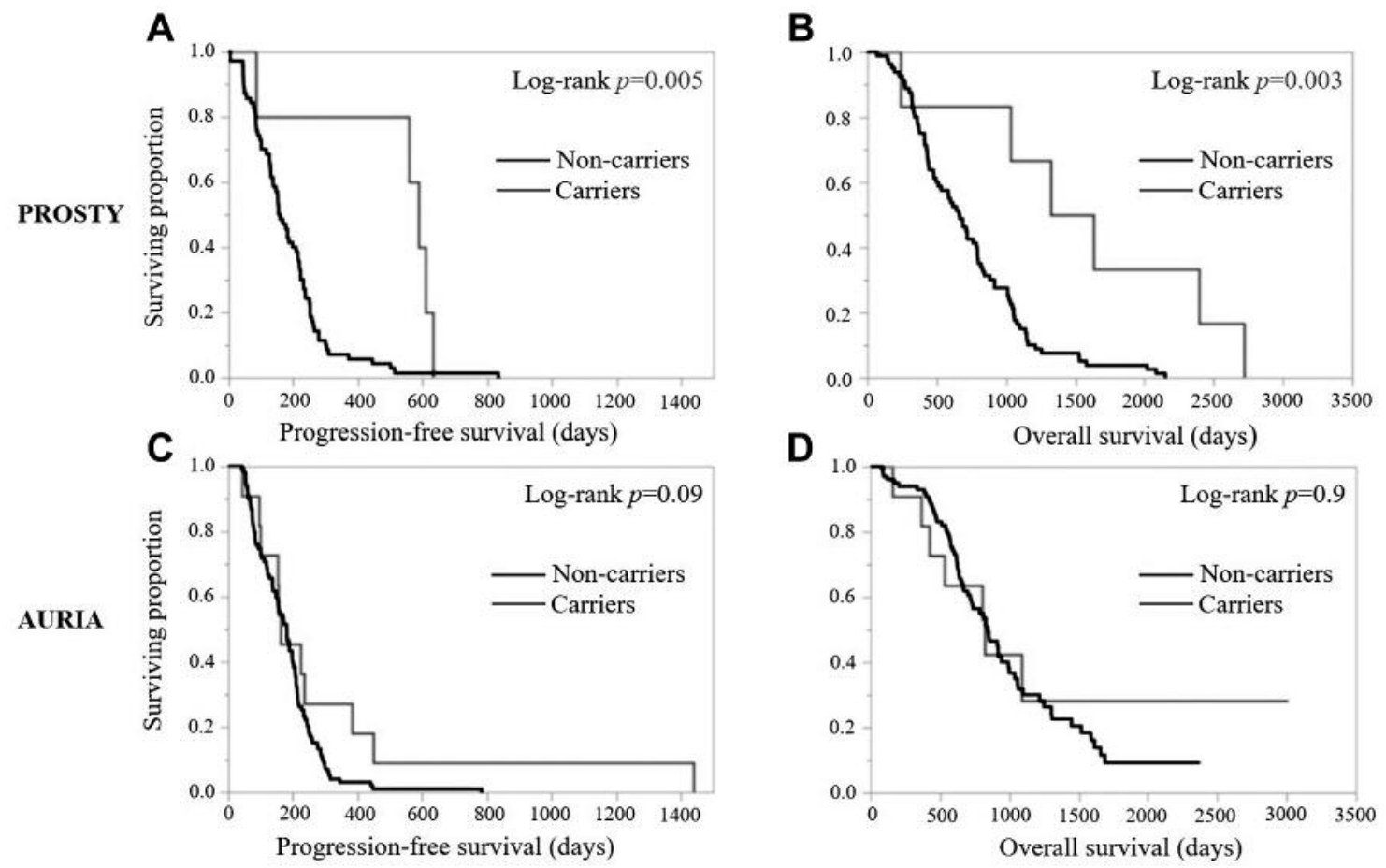

Figure 1. Kaplan-Meier plots of progression-free and overall survival after docetaxel first administration in the PROSTY (A and B, respectively) and Auria (C and D, respectively) patient cohorts.

Table II. Cox regression proportional hazards model for progression-free survival.

\begin{tabular}{|c|c|c|c|c|c|}
\hline \multirow[b]{2}{*}{ Variable } & & \multicolumn{2}{|c|}{ PROSTY } & \multicolumn{2}{|c|}{ Auria } \\
\hline & & $\mathrm{HR}(95 \% \mathrm{CI})$ & $p$-Value & $\mathrm{HR}(95 \% \mathrm{CI})$ & $p$-Value \\
\hline Variant rs77559646 & Non-carrier $v s$. carrier & $3.9(1.5-12)$ & 0.0027 & $2.4(1.1-6.1)$ & 0.024 \\
\hline PSA & Per change over entire range & $3.8(0.86-14)$ & 0.077 & $7.4(0.51-44)$ & 0.12 \\
\hline Time from diagnosis to docetaxel initiation & Per change over entire range & $0.63(0.32-1.2)$ & 0.14 & $0.50(0.19-1.3)$ & 0.15 \\
\hline Gleason score & $\geq 8 v s . \leq 7$ & $1.8(1.0-3.1)$ & 0.040 & $0.62(0.38-1.0)$ & 0.056 \\
\hline & Whole model & & $<0.0001$ & & 0.057 \\
\hline
\end{tabular}

CI: Confidence interval; HR: hazard ratio; PSA: prostate-specific antigen.

retrospective Auria cohort is its uncertainty about the endpoint time intervals due to uneven imaging and blood sampling. However, the diversity of the cohorts can also be considered as one of the strengths of the study. PROSTY, like all clinical trials, likely has a biased patient selection. On the other hand, the Auria cohort included a wider range of the docetaxel-treated patients with $\mathrm{PCa}$ as only the early chemohormonally treated cases were excluded. Our observation that the effect of the ANO7 variant was seen in both cohorts, although to a lesser degree in the Auria cohort, makes the results more useful in clinical practice.
This study strongly suggests that the ANO7 rs77559646 variant should be taken into account either alone or in combination with other (genetic) biomarkers when selecting treatment for patients with mCRPC.

\section{Conclusion}

We report here, for the first time, that men with mCRPC with a germline variant, rs77559646 in ANO7, have a better prognosis when given docetaxel than men without the variant. Another prospective clinical study is, however, 
warranted to confirm the results. In addition, functional analyses are needed to reveal the mechanism behind the observed treatment effect.

\section{Conflicts of Interest}

The Authors declare no potential conflicts of interest.

\section{Authors' Contributions}

Study concepts: EK, JS, PJB, OE; study design: EK, JS, PJB, OE; data acquisition: OE, IN, PT, P-LK-L, IL; quality control of data and algorithms: EK, JS, OE; data analysis and interpretation: EK; statistical analysis: EK; article preparation: all Authors; article editing: all Authors; article review: all Authors.

\section{Acknowledgements}

This study was financially supported by Worldwide Cancer Research (\#14-0089), the Sigrid Juselius Foundation, the Academy of Finland (\#310115), State Research Funding of Turku and Tampere University Hospitals, Cancer Foundation Finland sr, and Jane and Aatos Erkko Foundation.

\section{References}

1 Fitzpatrick JM, Bellmunt J, Fizazi K, Heidenreich A, Sternberg CN, Tombal B, Alcaraz A, Bahl A, Bracarda S, Di Lorenzo G, Efstathiou E, Finn SP, Fosså S, Gillessen S, KellokumpuLehtinen PL, Lecouvet FE, Oudard S, de Reijke TM, Robson CN, De Santis M, Seruga B and de Wit R: Optimal management of metastatic castration-resistant prostate cancer: Highlights from a european expert consensus panel. Eur J Cancer 50(9): 16171627, 2014. PMID: 24703899. DOI: 10.1016/j.ejca.2014.03.010

2 Gillessen S, Attard G, Beer TM, Beltran H, Bossi A, Bristow R, Carver B, Castellano D, Chung BH, Clarke N, Daugaard G, Davis ID, de Bono J, Borges Dos Reis R, Drake CG, Eeles R, Efstathiou E, Evans CP, Fanti S, Feng F, Fizazi K, Frydenberg M, Gleave M, Halabi S, Heidenreich A, Higano CS, James N, Kantoff P, Kellokumpu-Lehtinen PL, Khauli RB, Kramer G, Logothetis C, Maluf F, Morgans AK, Morris MJ, Mottet N, Murthy V, Oh W, Ost P, Padhani AR, Parker C, Pritchard CC, Roach M, Rubin MA, Ryan C, Saad F, Sartor O, Scher H, Sella A, Shore N, Smith M, Soule H, Sternberg CN, Suzuki H, Sweeney C, Sydes MR, Tannock I, Tombal B, Valdagni R, Wiegel $\mathrm{T}$ and Omlin A: Management of patients with advanced prostate cancer: The report of the advanced prostate cancer consensus conference APCCC 2017. Eur Urol 73(2): 178-211, 2018. PMID: 28655541. DOI: 10.1016/j.eururo.2017.06.002

3 Petrylak DP, Tangen CM, Hussain MH, Lara PN, Jones JA, Taplin ME, Burch PA, Berry D, Moinpour C, Kohli M, Benson MC, Small EJ, Raghavan D and Crawford ED: Docetaxel and estramustine compared with mitoxantrone and prednisone for advanced refractory prostate cancer. N Engl J Med 351(15): 15131520, 2004. PMID: 15470214. DOI: 10.1056/NEJMoa041318

4 Tannock IF, de Wit R, Berry WR, Horti J, Pluzanska A, Chi KN, Oudard S, Théodore C, James ND, Turesson I, Rosenthal MA, Eisenberger MA and TAX 327 Investigators: Docetaxel plus prednisone or mitoxantrone plus prednisone for advanced prostate cancer. N Engl J Med 351(15): 1502-1512, 2004. PMID: 15470213. DOI: 10.1056/NEJMoa040720

5 Mucci LA, Hjelmborg JB, Harris JR, Czene K, Havelick DJ, Scheike T, Graff RE, Holst K, Möller S, Unger RH, McIntosh C, Nuttall E, Brandt I, Penney KL, Hartman M, Kraft P, Parmigiani G, Christensen K, Koskenvuo M, Holm NV, Heikkilä K, Pukkala E, Skytthe A, Adami HO, Kaprio J and Collaboration NTSoCN: Familial risk and heritability of cancer among twins in Nordic countries. JAMA 315(1): 68-76, 2016. PMID: 26746459. DOI: $10.1001 /$ jama.2015.17703

6 Kaikkonen E, Rantapero T, Zhang Q, Taimen P, Laitinen V, Kallajoki M, Jambulingam D, Ettala O, Knaapila J, Boström PJ, Wahlström G, Sipeky C, Pursiheimo JP, Tammela T, Kellokumpu-Lehtinen PL, PRACTICAL Consortium, Fey V, Maehle L, Wiklund F, Wei GH and Schleutker J: ANO7 Is associated with aggressive prostate cancer. Int J Cancer 143(10): 2479-2487, 2018. PMID: 30157291. DOI: 10.1002/ijc.31746

7 Bera TK, Das S, Maeda H, Beers R, Wolfgang CD, Kumar V, Hahn Y, Lee B and Pastan I: NGEP, a gene encoding a membrane protein detected only in prostate cancer and normal prostate. Proc Natl Acad Sci USA 101(9): 3059-3064, 2004. PMID: 14981236. DOI: 10.1073/pnas.0308746101

8 Kiessling A, Weigle B, Fuessel S, Ebner R, Meye A, Rieger MA, Schmitz M, Temme A, Bachmann M, Wirth MP and Rieber EP: D-TMPP: A novel androgen-regulated gene preferentially expressed in prostate and prostate cancer that is the first characterized member of an eukaryotic gene family. Prostate 64(4): 387-400, 2005. PMID: 15761874. DOI: 10.1002/pros.20250

9 Suzuki J, Fujii T, Imao T, Ishihara K, Kuba H and Nagata S: Calcium-dependent phospholipid scramblase activity of TMEM16 protein family members. J Biol Chem 288(19): 13305-13316, 2013. PMID: 23532839. DOI: 10.1074/jbc.M113.457937

10 Hartzell HC, Yu K, Xiao Q, Chien LT and Qu Z: Anoctamin/TMEM16 family members are $\mathrm{Ca}^{2+}$-activated $\mathrm{Cl}$ channels. J Physiol 587(Pt 10): 2127-2139, 2009. PMID: 19015192. DOI: $10.1113 /$ jphysiol.2008.163709

11 Schreiber R, Uliyakina I, Kongsuphol P, Warth R, Mirza M, Martins JR and Kunzelmann K: Expression and function of epithelial anoctamins. J Biol Chem 285(10): 7838-7845, 2010. PMID: 20056604. DOI: 10.1074/jbc.M109.065367

12 Kellokumpu-Lehtinen PL, Harmenberg U, Joensuu T, McDermott R, Hervonen P, Ginman C, Luukkaa M, Nyandoto P, Hemminki A, Nilsson S, McCaffrey J, Asola R, Turpeenniemi-Hujanen T, Laestadius F, Tasmuth T, Sandberg K, Keane M, Lehtinen I, Luukkaala T, Joensuu H and PROSTY study group: 2-weekly versus 3-weekly docetaxel to treat castration-resistant advanced prostate cancer: A randomised, phase 3 trial. Lancet Oncol 14(2): 117-124, 2013. PMID: 23294853. DOI: 10.1016/S14702045(12)70537-5

13 Eisenhauer EA, Therasse P, Bogaerts J, Schwartz LH, Sargent D, Ford R, Dancey J, Arbuck S, Gwyther S, Mooney M, Rubinstein L, Shankar L, Dodd L, Kaplan R, Lacombe D and Verweij J: New response evaluation criteria in solid tumours: Revised RECIST guideline (version 1.1). Eur J Cancer 45(2): 228-247, 2009. PMID: 19097774. DOI: 10.1016/j.ejca.2008.10.026

14 Huizing MT, Misser VH, Pieters RC, ten Bokkel Huinink WW, Veenhof $\mathrm{CH}$, Vermorken JB, Pinedo HM and Beijnen JH: Taxanes: A new class of antitumor agents. Cancer Invest 13(4): 381-404, 1995. PMID: 7627725. DOI: 10.3109/07357909509031919 
15 Thadani-Mulero M, Nanus DM and Giannakakou P: Androgen receptor on the move: Boarding the microtubule expressway to the nucleus. Cancer Res 72(18): 4611-4615, 2012. PMID: 22987486. DOI: $10.1158 / 0008-5472$.CAN-12-0783

16 Bai S, Zhang BY and Dong Y: Impact of taxanes on androgen receptor signaling. Asian J Androl, 2018. PMID: 29900882. DOI: 10.4103/aja.aja_37_18

17 Antonarakis ES, Lu C, Wang H, Luber B, Nakazawa M, Roeser JC, Chen Y, Mohammad TA, Fedor HL, Lotan TL, Zheng Q, De Marzo AM, Isaacs JT, Isaacs WB, Nadal R, Paller CJ, Denmeade SR, Carducci MA, Eisenberger MA and Luo J: AR-V7 and resistance to enzalutamide and abiraterone in prostate cancer. $\mathrm{N}$ Engl J Med 371(11): 1028-1038, 2014. PMID: 25184630. DOI: 10.1056/NEJMoa1315815

18 Antonarakis ES, Lu C, Luber B, Wang H, Chen Y, Nakazawa M, Nadal R, Paller CJ, Denmeade SR, Carducci MA, Eisenberger MA and Luo J: Androgen receptor splice variant 7 and efficacy of taxane chemotherapy in patients with metastatic castrationresistant prostate cancer. JAMA Oncol 1(5): 582-591, 2015. PMID: 26181238. DOI: 10.1001/jamaoncol.2015.1341

19 Annala M, Vandekerkhove G, Khalaf D, Taavitsainen S, Beja K, Warner EW, Sunderland K, Kollmannsberger C, Eigl BJ, Finch D, Oja CD, Vergidis J, Zulfiqar M, Azad AA, Nykter M, Gleave ME, Wyatt AW and Chi KN: Circulating tumor DNA genomics correlate with resistance to abiraterone and enzalutamide in prostate cancer. Cancer Discov 8(4): 444-457, 2018. PMID: 29367197. DOI: $10.1158 / 2159-8290$.CD-17-0937

20 Castro E, Romero-Laorden N, Del Pozo A, Lozano R, Medina A, Puente J, Piulats JM, Lorente D, Saez MI, Morales-Barrera R, Gonzalez-Billalabeitia E, Cendón Y, García-Carbonero I, Borrega P, Mendez Vidal MJ, Montesa A, Nombela P, Fernández-Parra E, Gonzalez Del Alba A, Villa-Guzmán JC, Ibáñez K, Rodriguez-Vida A, Magraner-Pardo L, PerezValderrama B, Vallespín E, Gallardo E, Vazquez S, Pritchard CC, Lapunzina $\mathrm{P}$ and Olmos D: Prorepair-B: A prospective cohort study of the impact of germline DNA repair mutations on the outcomes of patients with metastatic castration-resistant prostate cancer. J Clin Oncol 37(6): 490-503, 2019. PMID: 30625039. DOI: $10.1200 / J C O .18 .00358$
21 Ahlgren GM, Flodgren P, Tammela TLJ, Kellokumpu-Lehtinen P, Borre M, Angelsen A, Iversen JR, Sverrisdottir A, Jonsson E, Sengelov L and 12 IotSPCSN: Docetaxel versus surveillance after radical prostatectomy for high-risk prostate cancer: Results from the prospective randomised, open-label phase 3 scandinavian prostate cancer group 12 trial. Eur Urol 73(6): 870876, 2018. PMID: 29395502. DOI: 10.1016/j.eururo.2018. 01.012

22 Kellokumpu-Lehtinen PL, Hjälm-Eriksson M, ThellenbergKarlsson C, Åström L, Franzen L, Marttila T, Seke M, Taalikka M, Ginman C and SPCG-13: Toxicity in patients receiving adjuvant docetaxel + hormonal treatment after radical radiotherapy for intermediate or high-risk prostate cancer: A preplanned safety report of the SPCG-13 trial. Prostate Cancer Prostatic Dis 15(3): 303-307, 2012. PMID: 22546837. DOI: 10.1038/pcan.2012.13

23 Kellokumpu-Lehtinen PL, Hjälm-Eriksson M, ThellenbergKarlsson C, Åström L, Franzen L, Fransson AS, Leskinen M, Zeke M, Huttunen T, Ginman $\mathrm{C}$ and Investigators of the Scandinavian Prostate Cancer Study No. 13: Docetacel versus surveillance after radical radiotherapy for intermediate- or highrisk prostate cancer - results from the prospective, open-label phase III SPCG-13 Trial. Eur Urol, 2019 (in press). PMID: 31443961. DOI: $10.1016 /$ j.eururo.2019.08.010
Received August 29, 2019

Revised September 16, 2019 Accepted September 17, 2019 